\section{Effectiveness of Houseplants in Reducing the Indoor Air Pollutant Ozone}

\author{
Heather L. Papinchak ${ }^{1}$, E. Jay Holcomb ${ }^{2,4}$, \\ Teodora Orendovici Best ${ }^{3}$, and Dennis R. Decoteau ${ }^{2}$
}

\begin{abstract}
AdDitional INDEX WORDs. mitigation, depletion rates, foliage
Summary. Three common indoor houseplants, snake plant (Sansevieria trifasciata), spider plant (Chlorophytum comosum), and golden pothos (Epipremnum aureum), were evaluated for their species effectiveness in reducing ozone concentrations in a simulated indoor environment. Continuously stirred tank reactor (CSTR) chambers housed within a greenhouse equipped with a charcoal filtration air supply system were used to simulate an indoor environment in which ozone concentrations could be measured and regulated. Ozone was injected into the chambers and when concentrations reached $200 \pm 5 \mathrm{ppb}$, the ozone-generating system was turned off and ozone concentrations over time (ozone was monitored every 5-6 min in each chamber) were recorded until about $<5 \mathrm{ppb}$ were measured in the treatment chamber. On average, ozone depletion time (time from when the ozone generating system was turned off at $\approx 200 \mathrm{ppb}$ to $<5 \mathrm{ppb}$ in the chamber) ranged from 38 to $120 \mathrm{~min}$ per evaluation. Ozone depletion rates were higher within chambers that contained plants than within control chambers without plants, but there were no plant species differences.
\end{abstract}

$\mathrm{I}$ ndoor air pollution is ranked as one of the world's greatest public health risks (Wolverton, 1997). The United Nations Development Program estimated in 1998 that over 2 million humans die each year due to the persistence of deleterious indoor air (Brennan and Withgott, 2005). It has also been estimated that globally 14 times as many deaths occur from poor indoor air quality compared with ambient air pollution (Brennan and Withgott, 2005).

Because humans in industrialized countries spend about of $80 \%$ to $90 \%$ of their time indoors (Orwell et al., 2004; Wolverton, 1997), negative societal consequences due to polluted indoor air can be great (Fisk and Rosenfeld, 1997). For example, the cost of unhealthy indoor air in Australia has been estimated at $\$ 12$ billion annually due to losses in productivity, higher medical costs, more absenteeism, and lower earnings (Wood, 2003). In addition, the health burden associated with indoor air pollution does not

We thank James Savage and Jonathan Ferdinand for providing technical assistance.

${ }^{1}$ Department of Economics, Environmental Resources Management, The Pennsylvania State University, University Park, PA 16802

${ }^{2}$ Department of Horticulture, The Pennsylvania State University, University Park, PA 16802

${ }^{3}$ School of Forest Resources, The Pennsylvania State University, University Park, PA 16802

${ }^{4}$ Corresponding author. E-mail: ejh3@psu.edu. appear to be equal for developing and developed countries. Australia's Commonwealth Science Council has suggested that 9 of 10 deaths due to indoor air are experienced by the developing world (Brennan and Withgott, 2005).

Ozone $\left(\mathrm{O}_{3}\right)$, a photochemical oxidant with a redox potential of $+2.07 \mathrm{~V}$, is one of the most powerful naturally occurring oxidants (Maroni et al., 1995; Mustafa, 1990). It is considered a secondary ambient pollutant and one of the components of tropospheric smog, which can adversely affect human health and property (Mustafa, 1990). Ozone is produced within the troposphere by chemical reactions involving free radicals. It is formed during the reaction of carbon monoxide (CO) and volatile organic compounds (VOCs) in the presence of nitrogen oxides $\left(\mathrm{NO}_{\mathrm{X}}\right)$, oxygen and sunlight. There is strong evidence to suggest that average ozone concentrations have been rising during the past century as a result of increased input of the precursors of ozone into the atmosphere (Mustafa, 1990). Automobiles are the principal contributors to secondary tropospheric ozone generation (Maroni et al., 1995).

Ozone as an indoor air pollutant can be prevalent in homes and offices due to infiltration of outdoor ambient air indoors (Weschler, 2000). Ozoneemitting equipment such as copy machines, laser printers, ultraviolet lighting, and some electrostatic air purification systems may also contribute to indoor ozone levels (Maroni et al., 1995; Weschler, 2000). Ozone generation from appliances such as photocopiers on average yield 5.2 $\mathrm{mg} \cdot \mathrm{h}^{-1}$ and laser printers on average produce $1.2 \mathrm{mg} \cdot \mathrm{h}^{-1}$; however, concentrations could vary based on equipment maintenance (Black and Worthan, 1999; Weschler, 2000). Depending on the air exchange rates between outdoor and indoor environments, indoor air has been reported to contain from $10 \%$ to $50 \%$ of outdoor values (Weschler, 2006) to five to seven times the contaminant concentrations of ambient urban air (Brown et al., 1994; Orwell et al., 2004).

The principal groups at risk to ozone toxicity are organisms in which the primary route of exposure is via inhalation (Wright and Welbourn, 2002). Daily inhalation of indoor ozone for these organisms (such as humans) are estimated to be between $25 \%$ and $60 \%$ of total ozone intake (Weschler, 2006). Major toxic effects of ozone in humans include alterations in pulmonary function in addition to cellular and biochemical endpoints (Wright and Welbourn, 2002). Exposure to ozone also may result in pulmonary edema, hemorrhage, inflammation, and extensive lesions on the lung tissue, trachea, and upper bronchi (Mehlman and Borek, 1987).

Indoor exposures to ozone are often accompanied by exposure to the

\begin{tabular}{llll}
\hline $\begin{array}{l}\text { Units } \\
\begin{array}{l}\text { To convert U.S. to SI, } \\
\text { multiply by }\end{array}\end{array}$ & U.S. unit & SI unit & $\begin{array}{l}\text { To convert SI to U.S., } \\
\text { multiply by }\end{array}$ \\
\hline 0.0283 & $\mathrm{ft}^{3}$ & $\mathrm{~m}^{3}$ & 35.3147 \\
6.4516 & $\mathrm{inch}^{2}$ & $\mathrm{~cm}^{2}$ & 0.1550 \\
28,350 & $\mathrm{Oz}$ & $\mathrm{mg}$ & $3.5274 \times 10^{-5}$ \\
1 & $\mathrm{ppb}$ & $\mathrm{nL} \cdot \mathrm{L}^{-1}$ & 1 \\
$\left({ }^{\circ} \mathrm{F}-32\right) \div 1.8$ & ${ }^{\circ} \mathrm{F}$ & ${ }^{\circ} \mathrm{C}$ & $\left(1.8 \times{ }^{\circ} \mathrm{C}\right)+32$
\end{tabular}


products of ozone-initiated oxidative reactions (such as isoprenes, styrenes, terpenes, sesquiterpenes, and unsaturated fatty acids) (Weschler, 2004). The average daily intakes of ozone oxidative products are roughly onethird to twice the average daily intake of ozone alone (Brown et al., 1994). Some of the oxidative products of ozone that are known or suspected to adversely affect human health include formaldehyde, acrolein, hydrogen peroxides, and fine and ultrafine particles (Weschler, 2004). Common indoor sources of reactive chemicals to ozone include occupants themselves, soft woods, linoleums, certain paints, polishes, cleaning products, soiled fabrics, and soiled ventilation filters. Indirect evidence supports connections between human morbidity/mortality and exposures to indoor ozone and its oxidative products (Weschler, 2006).

As indoor air pollution poses concerns for human health, costeffective and easy-to-implement methods are needed to eliminate or reduce concentrations. Activated charcoal filters reduce air pollutants but installation and maintenance costs can be high (Wolverton, 1997). As an alternative, foliage plants could be used to sequester some types of air pollution, although their effectiveness appears to be plant species specific and air pollutant dependent (Wolverton, 1986).

Wolverton (1984) evaluated common foliage plants in controlled chambers (that simulated indoor environments) for their ability to reduce concentrations of several air pollutants. Depletion rates of known concentrations of air pollutants within the enclosed chambers containing plants were measured. Wolverton concluded that of the taxa selected, common spider plant and golden pothos most effectively reduced various air pollution concentrations (e.g., formaldehyde, nitrogen dioxide, and carbon monoxide) from closed chambers (Wolverton, 1984, 1986). Because ozone was not one of the indoor air pollutants evaluated in the previous study (Wolverton, 1984) and it is an important indoor air pollutant for which mitigation methods are limited, the objective of the current study was to determine the effectiveness of using common foliage houseplants in reducing concentrations of ozone within a simulated indoor environment.

\section{Materials and methods}

Plant material AND growing CONDITIONs. Three plants species, snake plant, spider plant, and golden pothos, were evaluated for their effectiveness in reducing ozone concentrations in a simulated indoor environment. These plant species were chosen because of their popularity as indoor houseplants (primarily due to their low cost, low maintenance, and rich foliage) and their previously reported ability to reduce air pollutants other than ozone (Wolverton, 1986, 1997).

Plants were grown in greenhouse pots (one plant per pot) containing peatlite commercial growing mix (Sunshine \#4; Sun Gro Horticulture, Bellevue, WA) in a greenhouse at The Pennsylvania State University campus in University Park. Watering, fertilization, and pest control were conducted according to recommendations and ensured good healthy plant growth before and during the experiments.

OZONE EXPOSURE AND MONITORING. Four continuously stirred tank reactor (CSTR) chambers (2 $\mathrm{m}^{3}$ volume) covered with clear Teflon ${ }^{\circledR}$ film and situated within a greenhouse equipped with a charcoal filtration air supply system (resulting in ambient levels of ozone within the greenhouse of $<5 \mathrm{ppb}$ ) were used to simulate an indoor environment in which ozone concentrations were measured and regulated. The CSTR chambers previously described by Heck et al. (1978) had an air flow circulation within the chambers of $\approx 4.5 \mathrm{~m}^{3} \cdot \mathrm{min}^{-1}$. All of the CSTR chambers were air tight when sealed and were maintained under greenhouse conditions [e.g., photosynthetic photon flux $(P P F)$, humidity, and temperature]. Ozone was injected into the chambers via a controllable micrometering system and concentrations were monitored with an ozone analyzer (TECO model 49; Thermo Electron Corp., Hopkinton, MA) and data logger/computer recording system. Impeller fans ensured mixing of the gases within the chambers. Once the ozone concentrations within the chambers reached $200 \pm 5 \mathrm{ppb}$, the ozone-generating system was turned off and the ozone depletion rate (time to $<5 \mathrm{ppb}$ ) for each chamber was recorded at approximate 5- to 6-min intervals. This depletion rate was used as an indicator that the aerial portion of the plant was assisting in ozone mitigation. Air circulation within the chambers continued during all trials.

Five spider plants, five golden pothos plants, and two snake plants (because of their larger size) per replication were used in this evaluation. During the evaluations, the top part of each pot was enclosed with plastic sheeting in such a manner that only the aerial portion of the plants was exposed to ozone. One chamber that did not contain any plants served as control.

At the completion of the evaluations, leaf surface area and stomatal conductance $\left(g_{s}\right)$ of the plants were measured. Leaf surface area $\left(\mathrm{cm}^{2}\right)$ was measured via an area meter (LI-3100; LI-COR, Lincoln, NE) on all the plants within the individual chambers and is reported as leaf area per chamber. $G_{\mathrm{S}}\left[\right.$ water $\left.\left(\mathrm{mol} \cdot \mathrm{m}^{-2} \cdot \mathrm{s}^{-1}\right)\right]$ was measured midleaf on representative midaged leaves (while avoiding large veins or any patterns of variegation) on individual plants via a portable photosynthesis system (LI-6400; LICOR) equipped with a leaf chamber fluorometer and is reported as $g s$ average per chamber.

STATISTICAL DESIGN AND ANALYSIS. The experiment was conducted as a completely randomized design with plant species as the main effect replicated six times (trials) over the course of 3 d (27 June 2006, 28 June 2006, and 3 July 2006) under similar environmental conditions (Table 1). Three of the trials were conducted during the late morning (AM) and three trials were conducted during the early afternoon (PM); day and time of day (AM or PM) were noted for each trial. The plant species evaluated were alternated among specific chambers during the replications over time to exclude any possible chamber effect. The same individual plants within species were used for all trials.

Data were analyzed using Minitab (release 14; Minitab, State College, PA), Excel (Microsoft, Redmond, WA), and SAS (SAS Institute, Cary, NC). Significant results are reported at the level of $\alpha=0.05$ (unless otherwise noted). The slope was calculated as the derivative of the depletion curve over time $s=\left[o\left(t_{0}\right)-o\left(t_{1}\right)\right] /\left(t_{0}-t_{1}\right)$, where $o(\mathrm{t})$ represents the value of 
ozone at time t. Ozone depletion depends on the uptake of ozone by the plant species, therefore it was not appropriate to use a simple decay formula. The absolute value of slope of the depletion curves (i.e., ozone concentration per time interval), time to $50 \%$ reduction of ozone, and time to less than 5 ppb ozone within the chamber (the point at which the trial were ended) were used to account for the ozone depletion rate for each treatment. General Linear Model (GLM) was used to determine the significant factors affecting the depletion curves. Day, time of day (AM or PM), chamber, and treatments (e.g., species /control) as well as gs and total plant leaf area were all considered in the statistical model.

\section{Results}

Analysis of variance of the six trials determined that there was no day or time of day (AM vs. PM) effect on the ozone depletion rates (as measured as absolute slopes of the curves) among the treatments (Table 2). The negative slopes of the ozone curves from the experimental treatments indicated that ozone was mitigated from the chambers among the four treatments (Fig. 1).

There was an effect of treatment on time to $<5 \mathrm{ppb}$ (the conclusion of the trial) and absolute slope of the ozone depletion curve (Table 3). Time to $<5 \mathrm{ppb}$ among treatments ranged from 38 to $120 \mathrm{~min}$. Any of the plant species treatments evaluated required a shorter time to reach $<5$ $\mathrm{ppb}$ than the control treatment that contained no plants. The absolute slope of the control treatment was the smallest and was significantly different from the golden pothos and snake plant treatments, but similar to the spider plant. There was no statistical difference among treatments in the amount of time for the ozone to reduce to $50 \%$ (data not presented).

There were statistical differences in $\mathscr{I}_{\mathrm{s}}$ (Table 4) among the plant species evaluated. The spider plant had the greatest conductance, while the golden pothos had the least, and snake plant was intermediate.

\section{Discussion}

Plant species evaluated in this study (snake plant, spider plant, and golden pothos) were effective in

Table 1. Environmental conditions of temperature and relative humidity in the continuously stirred tank reactor chambers during the six trials conducted in 2006 to test the effectiveness of houseplants in reducing ozone. PPF levels ranged from 150 to $200 \mu \mathrm{mol} \cdot \mathrm{m}^{-2} \cdot \mathrm{s}^{-1}$.

\begin{tabular}{lccc}
\hline Day & ${\text { Time of } \text { day }^{\mathrm{z}}}_{27}$ June & $\begin{array}{c}\text { Temp }\left({ }^{\circ} \mathrm{F}\right)^{\mathrm{y}} \\
(\mathbf{a v g} \pm \mathrm{SD})\end{array}$ & $\begin{array}{c}\text { Relative humidity } \\
(\%)(\mathbf{a v g} \pm \mathrm{SD})\end{array}$ \\
\multirow{2}{*}{ 28 June } & AM & $103.2 \pm 6.6$ & $59.2 \pm 3.4$ \\
& PM & $101.1 \pm 2.0$ & $55.0 \pm 2.6$ \\
2 July & AM & $98.2 \pm 3.6$ & $53.6 \pm 0.2$ \\
& PM & $98.3 \pm 3.3$ & $49.8 \pm 5.4$ \\
& AM & $87.9 \pm 2.4$ & $75.6 \pm 2.4$ \\
\hline
\end{tabular}

${ }^{\mathrm{z}} \mathrm{AM}=$ late morning, $\mathrm{PM}=$ early afternoon.

${ }^{\circ} \mathrm{C}=\left({ }^{\circ} \mathrm{F}-32\right) \div 1.8$

Table 2. Analysis of variance comparing day, time of day (late morning versus early afternoon), and plant species (snake plant, spider plant, and golden pothos) on absolute slope of the ozone depletion curves. ${ }^{\mathrm{z}}$

\begin{tabular}{lrccc}
\hline Source & df & Mean square & F & $P>$ F \\
\hline Day & 2 & 16.231 & 1.73 & 0.180 \\
Time of day & 1 & 1.918 & 0.20 & 0.652 \\
Plant species & 3 & 46.223 & 4.92 & 0.003 \\
Error & 224 & 9.400 & & \\
\hline
\end{tabular}

${ }^{2}$ Ozone concentrations among the plant species were sampled over time during the trials, and the absolute slope of the resulting ozone depletion curves was calculated as the derivative of the depletion curve over time $s=\left[o\left(t_{0}\right)-o\left(t_{1}\right)\right] /\left(t_{0}-\left(t_{1}\right)\right.$, where $o(\mathrm{t})$ represent the value of ozone at time $\mathrm{t}$

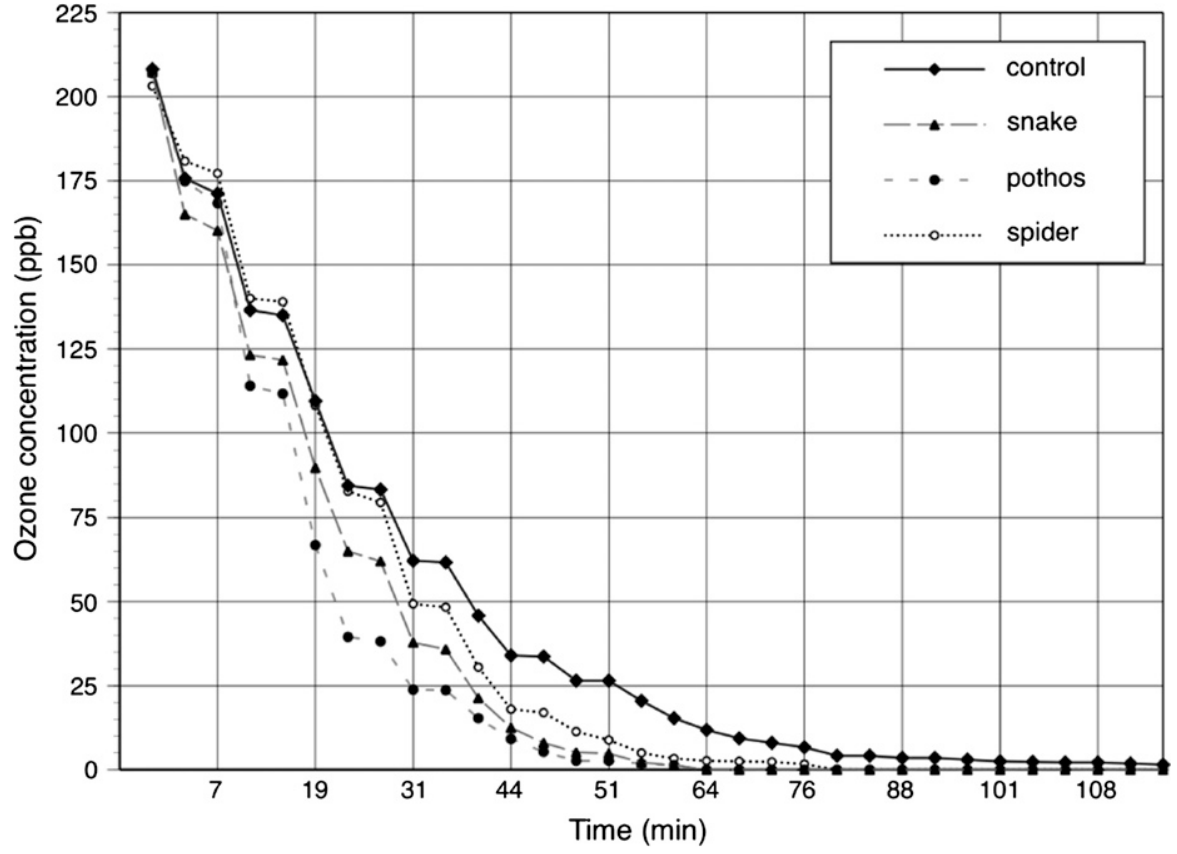

Fig. 1. Sampled ozone concentrations over time among the plant (chamber) treatments used to evaluate the effectiveness of houseplants in reducing ozone concentrations. When ozone concentrations reached about $200 \mathrm{ppb}$, the ozone generator was turned off (time $=0$ ) and ozone concentrations among the treatments over the ensuing time were measured (snake = snake plant, pothos = golden pothos, spider $=$ spider plant, control $=$ no plants, $\left.1 \mathrm{ppb}=1 \mathrm{~nL} \cdot \mathrm{L}^{-1}\right)$.

mitigating ozone (compared with a control that did not contain any plants) from the CSTR chambers that were used to simulate a controlled interior environment. These results are consistent to those reported by Wolverton $(1984,1986)$ using similar plant species for mitigation of VOCs. 
Table 3. Influence of selected houseplants on ozone concentrations within chambers over time. Once the ozone concentration within the chambers reached $200 \pm 5 \mathrm{ppb}$, the ozone-generating system was turned off and the ozone concentration for each chamber was recorded at approximate 6-min intervals. The control chamber did not contain any plants.

\begin{tabular}{lcc}
\hline Plant & $\begin{array}{c}\text { Time to }<\mathbf{5} \mathbf{~ p p b}^{\mathbf{z}} \\
\text { ozone }(\mathbf{m i n})\end{array}$ & $\begin{array}{c}\text { Absolute slope } \\
\text { of ozone curve }\end{array}$ \\
\hline Control & $74.8 \mathrm{a}^{\mathrm{x}}$ & $2.64 \mathrm{~b}$ \\
Spider plant & $50.3 \mathrm{~b}$ & $3.95 \mathrm{ab}$ \\
Golden pothos & $46.5 \mathrm{~b}$ & $4.33 \mathrm{a}$ \\
Snake plant & $46.3 \mathrm{~b}$ & $4.49 \mathrm{a}$ \\
Significance & $* * * \mathrm{w}$ & $* *$ \\
\hline
\end{tabular}

${ }^{\mathrm{z}} 1 \mathrm{ppb}=1 \mathrm{~nL} \cdot \mathrm{L}^{-1}$.

ySlope was determined as the average of the instantaneous rate of change (derivative) for each sampling period. ${ }^{x}$ Values followed by the same letter within a column did not differ according to Tukey's standardized range test at $P<0.05$.

${ }^{\mathrm{w}},{ }^{* *},{ }^{* *}$ Statistical significance at $P<0.01$ and $P<0.001$, respectively, by analysis of variance $(\mathrm{n}=5)$.

Table 4. $G_{S}$ rates and leaf surface area of houseplants evaluated for their effectiveness in reducing ozone concentrations within chambers.

\begin{tabular}{lcc}
\hline Plant & $\begin{array}{c}G_{\mathrm{S}} \\
{\left[\text { water }\left(\mathbf{m o l} \cdot \mathbf{m}^{-2} \cdot \mathbf{s}^{-1}\right)\right]}\end{array}$ & $\begin{array}{c}\text { Leaf surface area } \\
\left(\mathbf{c m}^{2} \text { per chamber }\right)^{\mathbf{z}}\end{array}$ \\
\hline Spider plant & $0.1184 \mathrm{a}^{\mathrm{y}}$ & $7,718.8$ \\
Snake plant & $0.0998 \mathrm{ab}$ & $14,711.0$ \\
Golden pothos & $0.0581 \mathrm{~b}$ & $13,227.7$ \\
Significance & $* * \mathrm{x}$ & na \\
\hline
\end{tabular}

${ }^{\mathrm{z}} 1 \mathrm{~cm}^{2}=0.1550$ inch $^{2}$.

'Values followed by the same letter within a column did not differ according to Tukey's standardized range test $(P<0.05)$.

${ }^{x},{ }^{*}$ Statistical significance at $P<0.01$ by analysis of variance $(\mathrm{n}=5), \mathrm{na}=$ statistics not available as values are per chamber and only one observation was recorded.

Although other studies have suggested differential VOC depletion rates for plant species (Wolverton, 1984), in the current study, we were unable to identify any interspecies differences in depletion rates for ozone.

A plant's ability to reduce concentrations of ozone in its surrounding environment appears to be dependent upon uptake of ozone through the stomata and subsequent detoxification reactions within the intracellular spaces. Therefore, the instantaneous rate at which plant surfaces absorb ozone would depend on the $g_{s}$ and the total leaf surface area of the plant species. Because $g_{s}$ per plant and total leaf area of the plants within the chambers varied among the treatments, it was not possible to determine if $g_{S}$ or total leaf area was the more important plant variable in mitigating ozone. Additional research with plants of varying $g_{S}$ and leaf area as well as alternative nonplant materials that increased the surface area are needed to further understand these variables before more precise plant recommendations can be made.

In previous research, emphasis had been placed on the ability of the indoor plant/substrate microcosm and soil to deplete contaminants more effectively (Orwell et al., 2004; Wolverton and Wolverton, 1993). Our study did not consider soil or microorganisms as factors in determining ozone mitigation; prospectively, we plan on exposing soil and microorganisms to ozone to determine their effect of indoor ozone depletion.

In conclusion, common houseplants reduce ozone concentrations in a simulated indoor setting. As a method to reduce airborne contaminants, plant implementation may be cost effective and readily applied throughout the world. In particular, the plant species evaluated in this study were common, inexpensive, and easy to grow and maintain. More information is needed on species effectiveness, the number of plants required per unit area, and other environment interactions (including light, temperature, and humidity) to develop more effective recommendations. Regardless, our results provide relevant evidence of a viable indoor ozone mitigation technique using common indoor plants that could have medical, environmental, and economic implications for developing and developed countries. Because indoor air pollution extensively affects developing countries (Brennan and Withgott, 2005; Smith, 2002), using plants as a mitigation method could serve as a cost-effective tool in the developing world where expensive pollution mitigation technology may not be economically feasible.

\section{Literature cited}

Black, M.S. and A.W. Worthan. 1999. Emissions from office equipment, p. 454-459. In: G. Raw, C. Aizlewood, and P. Warren (eds.). Indoor air 99. Vol. 2. Construction Research Communications, London.

Brennan, S. and J. Withgott. 2005. Environment: The science behind the stories. Pearson, San Francisco.

Brown, S.K., M.R. Sim, M.J. Abramson, and C.N. Gray. 1994. Concentrations of volatile organic compounds in indoor air: A review. Indoor Air 4:123-134.

Fisk, W.J. and A.H. Rosenfeld. 1997. Estimates of improved productivity and health from better indoor environments. Indoor Air 7:158-172.

Heck, W.W., R.B. Philbeck, and J.A. Dunning. 1978. A continuous stirred tank reactor (CSTR) system for exposing plants to gaseous contaminants: Principles, specifications, construction, and operation. U.S. Dept. Agr., Agr. Res. Serv. Publ. No. ARS-S-181.

Maroni, M., B. Seifert, and T. Lindvall (eds.). 1995. Indoor air quality: A comprehensive reference book. Elsevier Science, New York.

Mehlman, M.A. and C. Borek. 1987. Toxicity and biochemical mechanisms of ozone. Environ. Res. 42:36-53.

Mustafa, M.G. 1990. Biochemical basis of ozone toxicity. Free Radic. Biol. Med. 9:245-265.

Orwell, R.L., R.L. Wood, J. Tarran, F. Torpy, and M.D. Burchett. 2004. Removal of benzene by the indoor plant/substrate microcosm and implications for air quality. Water Air Soil Pollut. 157:193-207.

Smith, K.R. 2002. Indoor air pollution in developing countries: Recommendations for research. Indoor Air 12:198-207.

Weschler, C.J. 2000. Ozone in indoor environments: Concentration and chemistry. Indoor Air 10:269-288.

Weschler, C.J. 2004. New directions: Ozone-initiated reaction products 


\section{Research Reports}

indoors may be more harmful than ozone itself. Atmos. Environ. 38:5715-5718.

Weschler, C.J. 2006. Ozone's impact on public health: Contributions from indoor exposures to ozone and products of ozone-initiated chemistry. Environ. Health Perspect. 114:1489-1496.

Wolverton, B.C. 1984. The role of plants and microorganisms in assuring a future supply of clean air and water. Natl. Aeronautics Space Admin., Natl. Space Technol. Lab., Stennis Space Center, MS.
Wolverton, B.C. 1986. Houseplants, indoor air pollutants, and allergic reactions. Natl. Aeronautics Space Admin., Natl. Space Technol. Lab., Stennis Space Center, MS

Wolverton, B.C. 1997. How to grow fresh air. Penguin, New York.

Wolverton, B.C. and J.D. Wolverton. 1993. Plants and soil micro-organisms: Removal of formaldehyde, xylene and ammonia from the indoor environment. J. Mississippi Acad. Sci. 38(2):1 1-15.
Wood, R.A. 2003. Improving the indoor environment for health, well-being and productivity. In: Greening cities: A new urban ecology. 30 Apr. 2003. Australian Technology Park, Sydney, Australia.

Wright, D.A. and P. Welbourn. 2002. Environmental toxicology. Cambridge University Press, Cambridge, UK. 